\title{
受賞記念講演
}

熱間等方圧加圧 (HIP) 利用技術の研究開発

河合 伸泰

珠神戸製鋼所鉄鋼生産本部生産技術部， テ651 神戸市中央区脇浜町1-3-18.

\section{On the Application Technology of Hot Isostatic Pressing}

\begin{abstract}
Technology Administration Department, Production Group, Iron \& Steel Division, Kobe Steel Ltd., 1-3-18 Wakinohama-cho Chuo-ku, Kobe 651.
\end{abstract}

Nobuyasu Kawai

Received December 20, 1993

Hot isostatic pressing technology has been applied to produce new materials with high performance using gas atomized alloy powders as raw materials. The author has been studying the technology in order to extend the application field for a long time. High speed tool steels and alloy tool steels, bimetallic products lined with corrosion and wear resistant alloy powders, heat resistant superalloy disks etc. are described.

Mechanical and physical properties of PM high speed steels with and without a large amount of nitrogen were evaluated in comparison with conventional steels so that the difference in the roles of nitrogen and carbon in the steels and in the manufacturing processes could be made clear. The manufacturing process of bimetallic cylinders and valves and the alloy design of lining,especially the effects of alloying elements in co and $\mathrm{Ni}$ base alloys are discussed. As-HIP and HIP plus isothermal forging of superalloy disks were studied and isothermal forging of dual property disk made of different powders was also described.

\section{1 緒 言}

熱間等方圧加圧 (H I P) 法はBattelle研究所で19 50年代に開発され、わが国に於ける実用化は1960年代 後半の超硬合金への適用から始まった，金属系粉末の H I P処理技術は1970年代前半から欧米において工具 鋼、耐熱超合金で実用化が始まり、わが国では著者ら "が高速度工具鋼粉末のH I P 処理を実用化したのが 最初である.以下にはこの高速度工具鋼をH I Pを用
いた粉末治金法により製造して、特性の改善、また 粉末治金法独特の高窒素銼の製造と鋼中での窒素の役 割について述べる．また、耐触、耐摩耗粉末を表面に ライニングした複合材料、とくに $\mathrm{N} \mathrm{i}$ 基、C O 基の合 金設計についての研究結果を報告する．さらに通産省 の補助金やナショナルプロジェクトに参画して研究し た耐熱超合金のHＩＰ処理技術とHＩＰ処理材の超塑 性鍛造技術についても紹介する. 


\section{2 高速度工具鋼}

高速度工具鍴は従来の造塊（IM）法では凝固時に 炭化物が粗大化、偏析し、特性を少化させている. い っぽう、比表面積の大きい粉末を用いると I M法では 製造が不可能な高窒素（N) 鋼が製造出来る，以下に I M材を比較材としてガスアトマイズ粉末をH I P L た材料の特性、高N鋼の特性を述べる.

\section{1 窒素の吸收挙動}

高速度工具鋼には 2 5\%のVが通常含有してい

る. $177 \mu \mathrm{m}$ 以下のこれらの粉末を $\mathrm{N}_{2}$ ガス中、1423 $\mathrm{K} 、 3.6 \mathrm{ks}$ 保持した時の N含有量とV含有量の関係 をFig.1 に示す. NとVの含有量には綺麗な直線関係 がある.

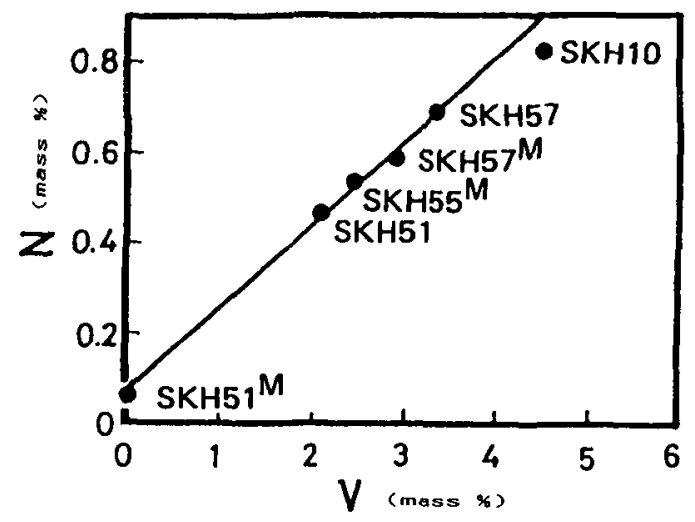

Fig.1 Relation between absorbed nitrogen and vanadium content when nitrided at $1423 \mathrm{~K}$.

このN含有量は窒化温度により異なり、また、窒化 速度は粉末粒度に影響される.この室化反応は粉末粒 子表面での $\mathrm{N}_{2}$ のNへの解離反応に律速されている.

\subsection{H I Pによる緻密化}

SKH 55粉末をカプセルに充填、脱気、密封後、1373 $\mathrm{K}$ で各時間保持した時の圧力之密度の関係を示したの がFig.2 である. ガスの昇圧に時間を要するので、保 持時間が $0 \mathrm{ks}$ でも70 MPaで100\%の密度が得られ、 $1.8 \mathrm{ks}$ では40 MPaの圧力で100\%に達する．密度が100\% に達するものの、条件により材料の曲げ強さが異なり 、粉末同土の結合状態が違っていることを示唆してい る2).

\section{3 熱間加工性}

SKR 10粉末のH I P固化材を 1023 - $1473 \mathrm{~K}$ で25m/s の高速引張試験を行い、絞り值て加工性を評価した。

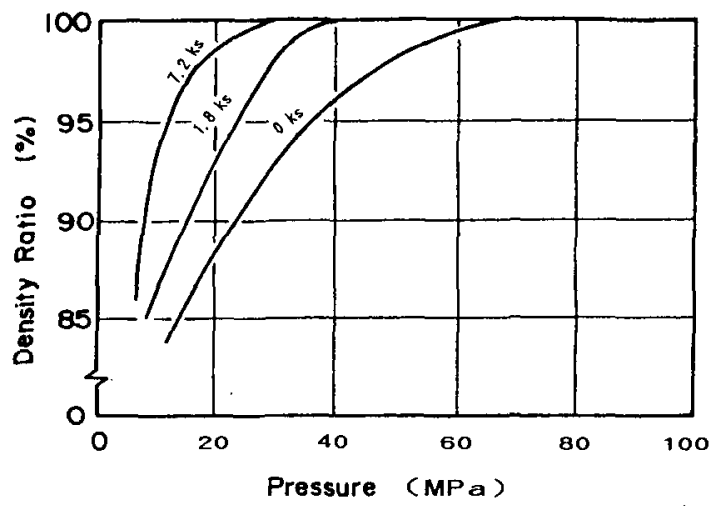

Fig.2 Density ratio as a function of pressure and time of $\mathrm{HIP}$ at $1373 \mathrm{~K}$.

その結果、I M材は粗大炭化物の割れや炭化物とマト リックスの界面で発生したボイドが連結して破断に至 るのに対して、H I P 処理材は細かいボイドが発生し て、絞り値も従来材よりも高い（Fig.3）

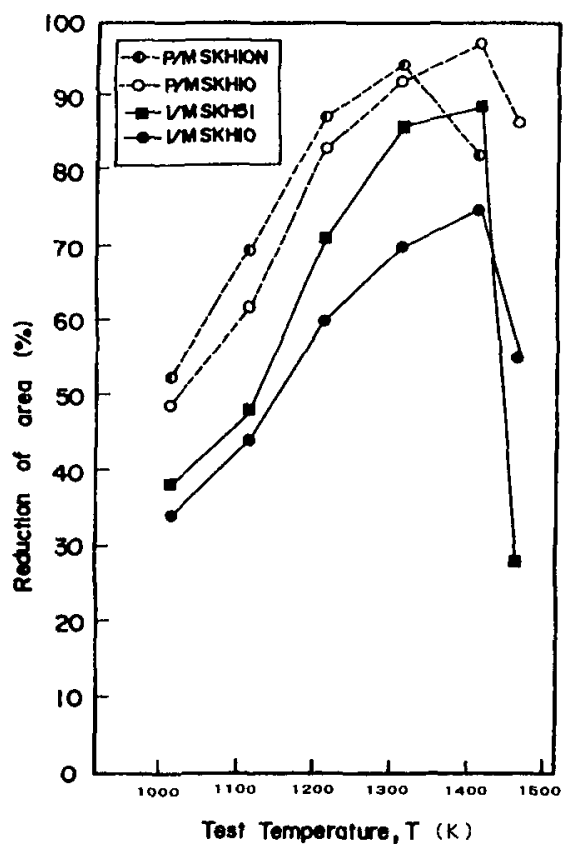

Fig.3 Results of high speed tensile tests at elevated temperature (strain rate: $25 \mathrm{~mm} / \mathrm{s}$, An gas).

\section{4 鋼中でのNの役割}

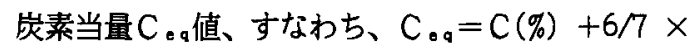


N(\%)が同じ值でもCをNで一部置換した鋼は初期溶 融温度が高く、CとNは鋼中で同じ影響を示さない， また、焼入硬さの挙動も同じでない゙)。溶体化状態の 各合金元素のマトリックスへの分配率を見ると、Nで Cを置換することによりW、Mo、Cのマトリックス 中への固溶量が増加し、MC炭化物中のW、MO、C が減少する゙) .このため、高温で保持後の常温硬さの 低下が大きく、耐熱性には少るものの、大越式摩耗試 験では、Nが多いほど酎磨耗性、とくに、耐凝着摩耗 性が改善される. (Fig.4)

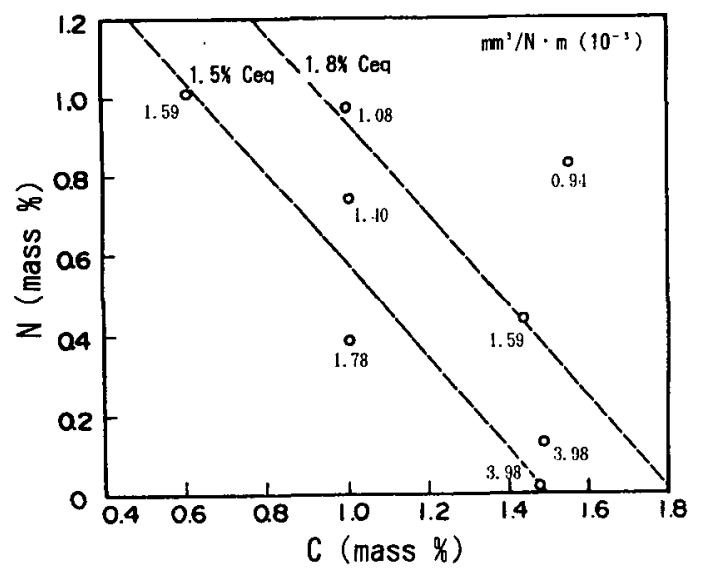

Fig.4 Relation between wear rate $\left(\mathrm{mm}^{3} / \mathrm{N}-\mathrm{m}\right)$ and $\mathrm{C}, \mathrm{N}$ content .

切削試験の結果でもN含有鋼はアブレッシブ摩耗に は劣るものの耐凝着摩耗、靬性に優れる（Fig.5）

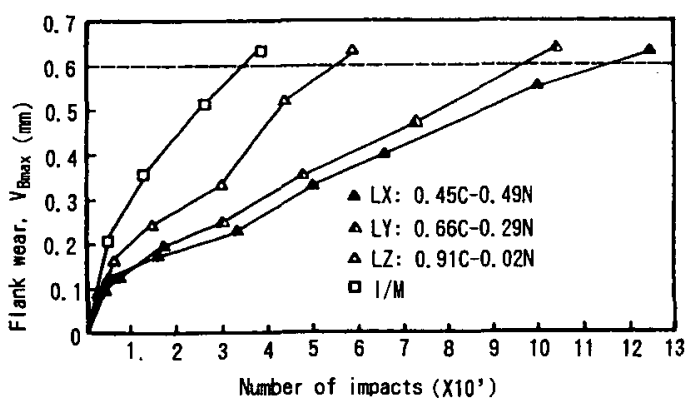

Fig. 5 Change in flank wear of SKH 51 series during intermittent cutting.
また、Nを含有しないHＩＰ処理材と従来材を比較 すると、H I Pした粉末治金材の摩耗が少なく、靱性 に優れることが判る.

\section{3 被合材料}

近年、各種産業機械における構成部品の高性能化の 要求に対して、拡散接合による複合材料の製造が注目 されている．粉末の加熱による焼結のみで接合するの でなく、等方圧を加えてHＩＰすることにより、処理 時間の短縮、特性の向上を図ることが行われている.

3.1 射出成形用シリンダー

\section{1 .1 製造方法}

Co基、Ni基の合金粉末をArガスアトマイズ法で製造 し、Fig.6 に示すSCM 440 製の円筒材とインナーカプ セルとの間隙に充埴、密封した. SCM 円筒材の結晶粒 が粗大化して、特性が劣化しないようにH I P処理温 度を出来るだけ低く抑えることが必要である．H I P 法の場合、ホッパー孔内面までライニング出来ること が特徵である5).(Photo.1)
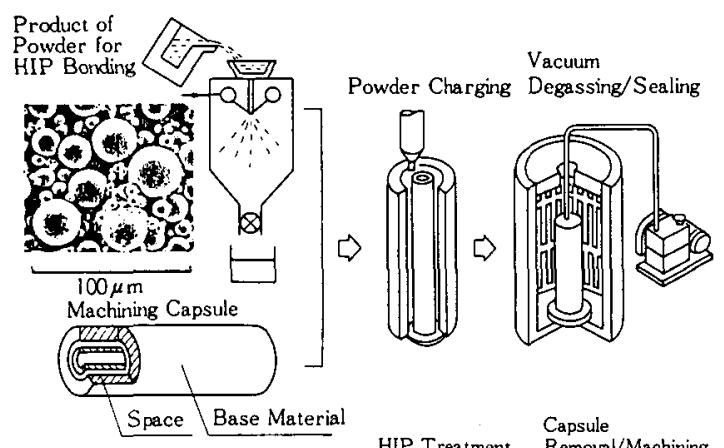

$$
\text { Space Base Material }
$$

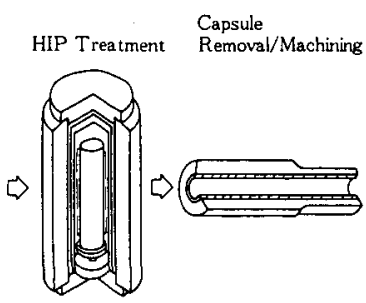

Fig.6 Manufacturing process for bimetallic cylinder through HIP.

\section{1 .2 C 基ライニング合金}

Table 1 に示すCo基ライニング合金を真空溶解、ガ スアトマイズして177 $\mu \mathrm{m}$ 以下にるい分け、1223K $\times 100 \mathrm{MPa} \times 10.8 \mathrm{ks}$ の条件でH I P処理を行った. このH I P材をTable 1 に示したCo基遠心鋳造合金、 $\mathrm{Ni}$ 基遠心鋳造合金、窒化鋼を比較材として腐食試験、 


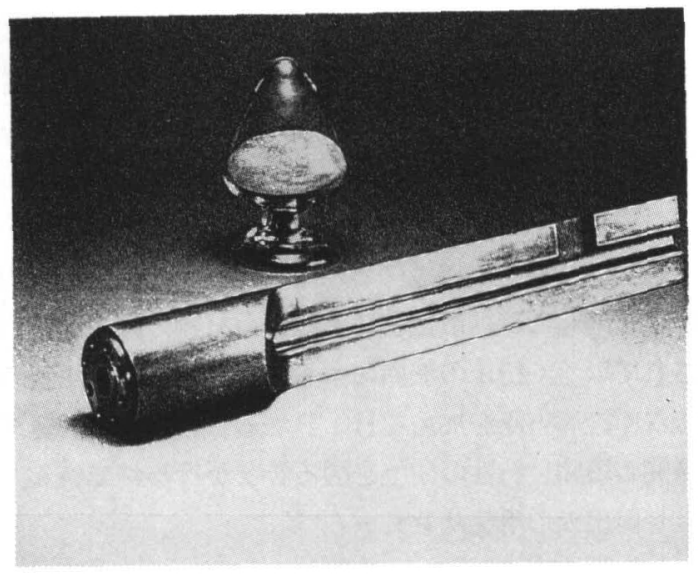

Photo. 1 Bimetallic cylinder for injection molding of engineering plastics.

摩耗試験を行った. $313 \mathrm{~K} て ゙ の ~ H C l 、 \mathrm{H}_{2} \mathrm{SO}_{4} 、 \mathrm{HNO}_{3} 、$ に対する耐食性はいずれも優れており、一般に良く使 われている窒化鋼よりも著しく優れている. (Fig.7)

また、大越式摩耗試験機の結果を Fig.8に示すが、 低摩擦速度域では窒化鋼の 3 倍、CO 基、Ni 基の遠 心鋳造合金の1.2 倍、高摩擦速度域では窒化鋼の20倍 以上、C 0 基遠心鋳造合金の2 倍、 $\mathrm{Ni}$ 基遠心鋳造合金の 6 倍の優れた值を HIP 材は示した.これらの結果は耐 食性に優れるCO-C 2 -Niのマトリックスに微細な硼化物 が均一に分布しているためと思われる.この合金は熱 膨張係数がベース材であるSaM 440 に近く、HIP 処理 や使用時の引張忘力が小さく、また、高温硬さにも優 れる.

\subsubsection{Ni基ライニング合金}

最近は合金に要求される特性もより高度になり、フ ッ素系等の樹脂にも優れるライニング合金が要求され ている. 従来から使用されているハステロイCよりも 耐摩耗性に優九、耐食性が同等に良い合金を開発する ことを目標に下記の実験を行った。

耐摩耗性を有する Ni 基の遠心鋳造合金( $\mathrm{Ni}-\mathrm{C}$ - Mo3Si-3B合金を取り上げ、マトリックスと矹化物間の腐 食電位を下げる目的で ひ を添加し、その影響を調べ た. Fig.9 に示す様にCuは1\%以上の添加で10\%AF に対 する耐食性が改善される. また、MoとCrの影響を見る とFig.10に示す様にHF、 $\mathrm{HNO}_{3}$ の両方に良い耐食性を示 すのはMo/Cr 比が1.0 付近である.HF への耐食性を重 視してMo/Cr 比を1.4としたC703合金(Ni-24Mo-17.5

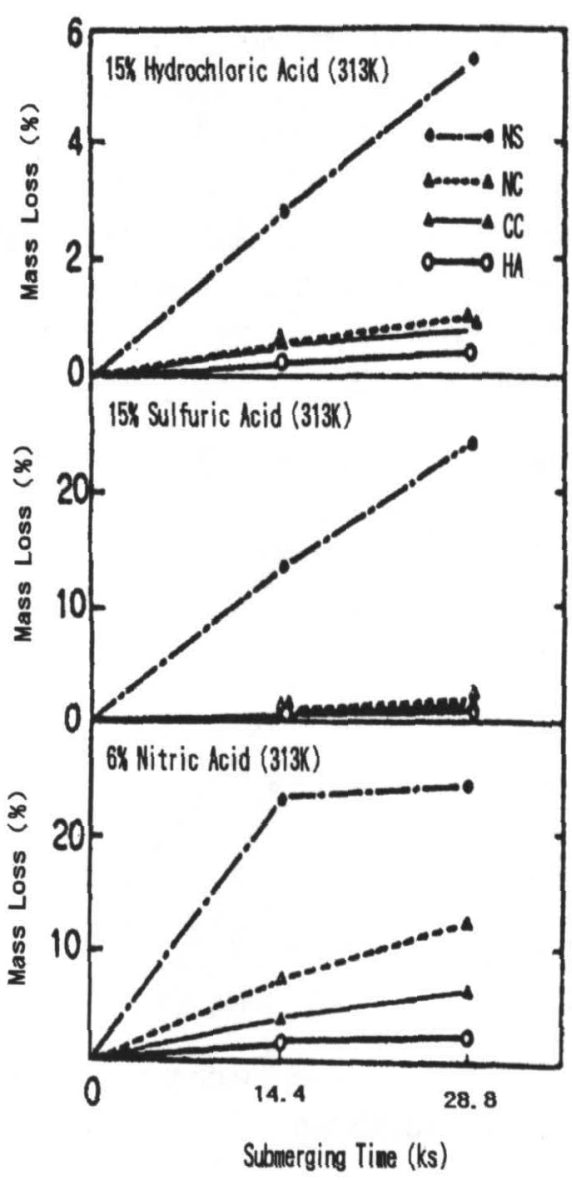

NS: Nitrided Steel

NC: Ni-base Centrifugal casting

CC : Co-base Centrifugal casting

HA: HIP'ed Alloy

Fig.7 Result of corrasion test .

Cr-3Si-3B-1Cu)はFig.11に示す様にHFに対してはハス テロイよ よりやや耐食性が良好であり、耐摩耗性は著 しく優れる. (Fig.12) 


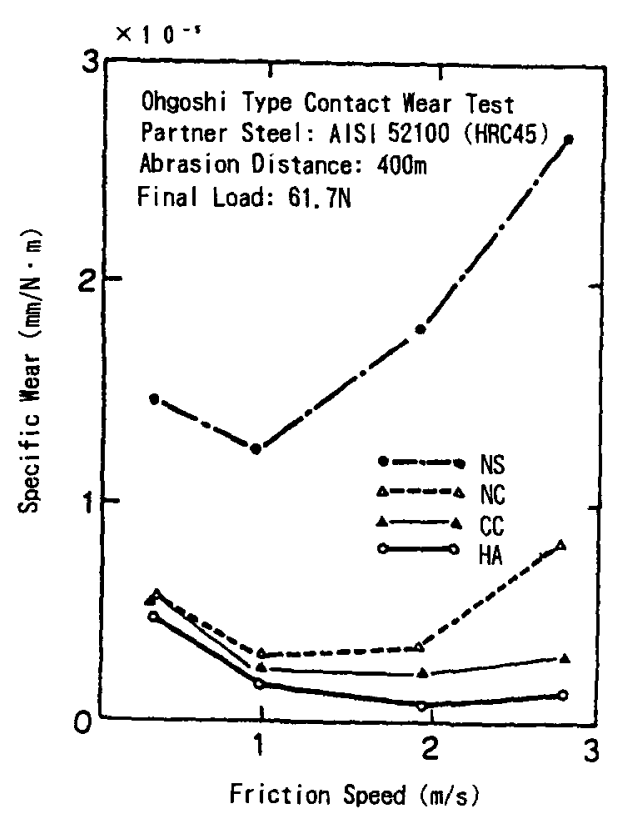

NS : Nitrided Steel

NC: Ni base Centrifugal Casting

$C C$ : Co-base Centrifugal Casting

HA: HI P'ed Alloy

Fig.8 Result of wear test.

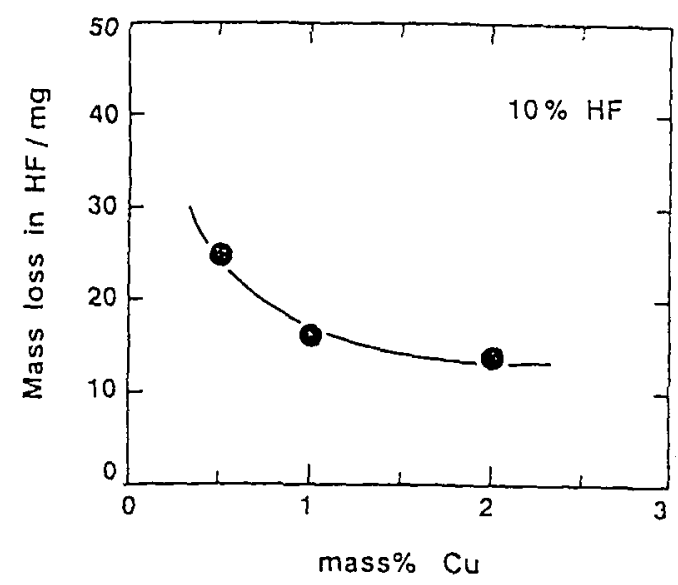

Fig.9 Effect of $\mathrm{Cr}$ content on mass lass of $\mathrm{Ni}$ $15 \mathrm{C}-15 \mathrm{MO}-3 \mathrm{Si}-3 \mathrm{~B}$ alloy in $10 \% \mathrm{~F}$.
以上、述べた複合材料はプラマグ用射出成形機の非 磁性シリンダー、1 軸、2 軸のシリンダー、圧延ロ一 ル、ローラー、金型、油井用バルブボディ等に応用さ れている6!.

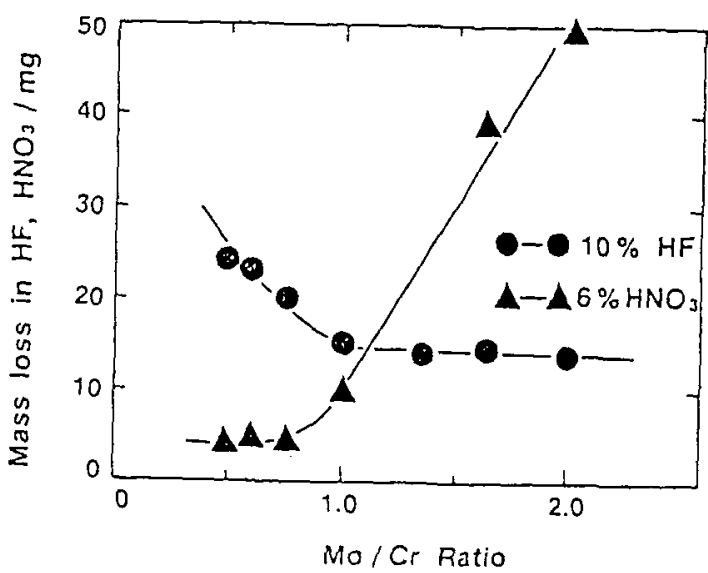

Fig. 10 Effect of Mo/Cr ratio on mass loss of $\mathrm{Ni}-$ $\mathrm{Cr}-\mathrm{Mo}-3 \mathrm{Si}-3 \mathrm{~B}-1 \mathrm{Cu}$ alloys in $\mathrm{HF}$ and $\mathrm{HNO}_{3}$.

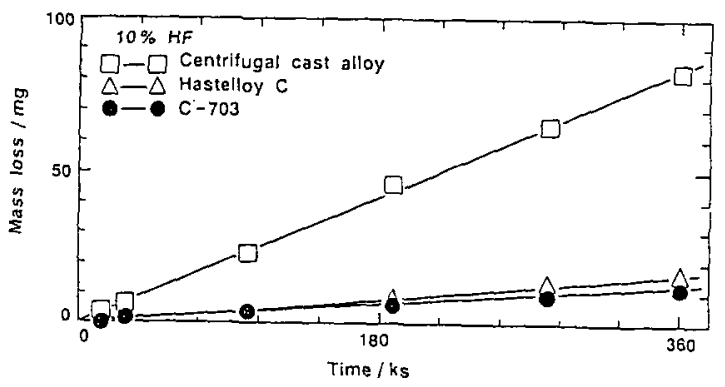

Fig. 11 Mass loss of alloys in 10\% F at 323K.

\section{4 耐熱超合金材料}

航空機エンジンの高性能化のために、アメリカでは 1970年代の始めから而熱超合金粉末を押出一超塑性鍜 
造法によりディスクに加工され、実用に供されている . わが国では1980年代の始めから政府の補助金やナシ ヨナルプロジェクトにより基盤技術の研究開発が行わ れてきた. 以下はその結果の一部であり、H I P - 超 塑性鍛造法とA s - H I P 法についての要約である.

粉末は真空溶解一Arガスアトマイズ法により製造さ れ、ふるい分け、脱気、密封、H I Pの工程を経てデ イスクが製造されるが、この製造工程で粉末をArガス 中、あるいは大気中で取り扱うかにより、機械的特性 に影響を及ぼす. Fig.12には歪み制御疲労試験の結果 を示す. 空気中でのハンドリングは元の粒子表面にMC 炭化物を析出させ、粒子の表面で破断に至るために著 しく疲労特性を低下させる7.

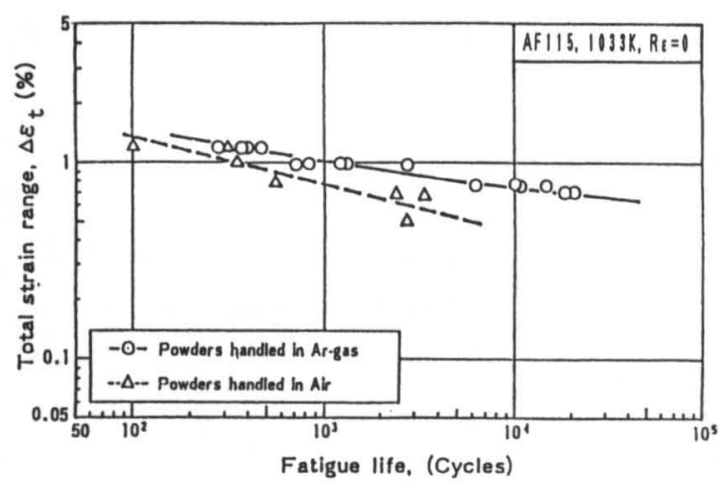

Fig.12 Influence of powder handling atmosphere on LFF life of as-HIPed AF115 alloy .

このAs-HIP法は発電用産業ガスタービンのロータに も適用されている81.

いっぽう、H I P - 超塑性鍛造法ではH I P 処理温 度と超塑性発現条件が深い関係があり ${ }^{91}$ 、再結晶温度 直上でH I Pされる.

また、ディスクの心部は低サイクル疲労特性が、 外周部は耐クリーブ特性が要求されるので、この異 なる性質を満足するために、前記のナショナルプロジ エクトで開発された合金粉末とAF 115合金粉末を組み 合わせた複合ディスクがH I Pされて、欠陥なく鍛造 されている.

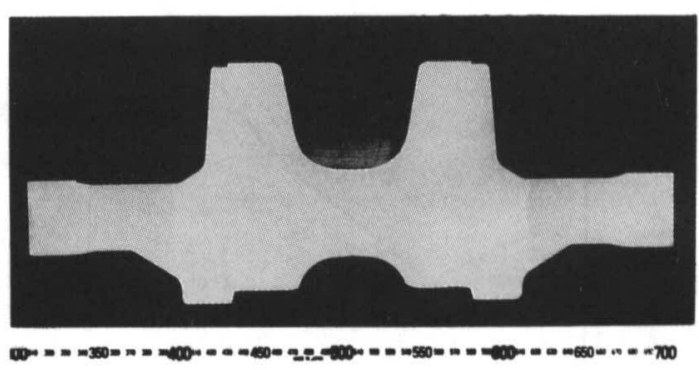

Photo.2 Superplastically forged dual-property disk .

\section{5 結 言}

以上、著者が長年にわたって H I P 利用技術の拡大 のために取り組んできた内容の一端を紹介した，上記 の研究遂行に当たって、(株神戸製鋼所の上司、共同研 究者の方々、その他種々ご協力、ご指導をいただいた 先生方に厚くお礼申し上げます. 最後に、良き後輩で 、共同研究者であった故滝川博君に感謝之哀悼の意を 表します.

\section{文 献}

1)辻 克己、河合伸泰、平野 稔、立野常男: 工具技 報,№.26 (1979), 9

2)河合伸泰、滝川 博、石井 勝、古田誠矢：粉体お よび粉末治金, 25 (1978),254

3)河合伸泰、平野 稔、立野常男、本間克彦：鉄と鋼 , $72(1986), 1921$

4)河合伸泰、立野常男、本間克彦：鉄と鋼，72(1986) , 1929

5)河合伸泰、滝川 博 : 粉体および粉末治金, 36 (1989),87

6)梅田孝一、滝川 博：溶接技術,7月号, (1987),65

7)J.H.Davidson \& C.Aubin:Proc.High Temp.Alloys for Cas Turbines, (1982),853

8)滝川 博、岩井健治、河合伸泰：塑性と加工, 27 (1986),397 